\title{
Evaluating the impact of food labeling in a vocational school: an open prospective pilot study
}

Damien GALTIER ${ }^{1}$, Clémence DACLIN ${ }^{1}$, Laurence PERRIN² ${ }^{2}$ Ilaria MONTAGNI ${ }^{3}$

${ }^{1}$ Cellule de Recherche En Soin Paramédical et Prévention (CRESP), FH Manhès Hospital Center, 91700 Fleury-Mérogis

${ }^{2}$ Agence Régionale de Santé (ARS) Ile de France, 35, Rue de la Gare, 75019 Paris

${ }^{3}$ Centre de Recherche U1219 Bordeaux Population Health (BPH), 33000 Bordeaux

DECLARATION OF CONFLICT OF INTERESTS

Authors declare no conflict of interests.

\section{ACKNOWLEDGEMENTS}

This study was conducted by the Paramedical Care Research Unit (CRESP) of the Frédéric Henri Manhès Hospital Centre (Fleury-Mérogis, Ile de France) as part of the 2018 call for initiatives in health promotion launched by the Ile-de-France Regional Health Agency (ARS IDF). The catering company Elior was in charge of the distribution of meals.

CORRESPONDING AUTHOR

Damien GALTIER, Dietician, Nutritionist, Coordinator of the Research in Paramedical Care, CRESP, FH Manhès Hospital Center, 8 rue Roger Clavier, 91700 Fleury-Merogis

Telephone number: +33(0)169256461

Email: damien.galtier@ch-manhes.fr 


\section{ABSTRACT}

Background: In October 2017, France adopted the Nutri-Score label as the official food label to display on industrial food packaging. School mass catering is recognized as a substantial contributor to individual diet.

Objective: Evaluating the impact of the food label Nutri-score on food choices of students at a school self-service restaurant and at home.

Methods: Longitudinal open prospective pilot study conducted in the self-service restaurant of a vocational school in France in 2019. After a survey among guests (T0), food products labeled with the Nutri-Score were presented to consumers on the menus at the entrance and directly on the food dishes at the counters (T1). The intervention was supplemented by a counseling service on healthy diet conducted by a nutritionist (T2).

Results: We observed a decrease in students' consumption of sweet products (57\%).

Similarly, the self-service catering staff observed at the end of T1 a decrease in food leftovers categorized as less healthy. The implementation of the counseling service at T2 was significantly associated with a higher consumption of fruits and vegetables $(\mathrm{P}<.001)$, healthier eating habits at home $(\mathrm{P}<.001)$, more home cooking $(\mathrm{P}<.02)$, and an increased will to check for the presence of the Nutri-Score labels on supermarket food items $(\mathrm{P}<.001)$.

Conclusions: After the display of the Nutri-Score label, we observed an improvement in students' diets. However, results were significant only when the Nutri-Score was associated with a counseling service. 


\section{INTRODUCTION}

Helping consumers make healthier food choices is a major challenge for chronic disease prevention. Among promising interventions, simplified nutrition labels on food packaging can help consumers make healthier food choices by providing quick and simple information on the nutritional quality of food products (1). Many countries have introduced food labelling on industrial food products. In France, the Ministry of Health recognized the Nutri-Score as the official national food label $(2,3)$. The Nutri-Score is a food label derived from the British Food Standards Agency's (FSAm-NPS) nutrient profiling system $(4,5)$. To classify each product, international research teams developed a score taking into account, per 100 grams of product, the content of nutrients and foods to be promoted (fibers, proteins, fruits and vegetables) and nutrients to be limited (high-calories, saturated fatty acids, sugars, salt) (5-7). Based on an algorithmic calculation, a score is obtained and food products are assigned a letter (from A to $\mathrm{E}$ ) associated with a color (from green to red), ranging from a "preferable score" (A, B) to a "detrimental score" $(\mathrm{C}, \mathrm{D}, \mathrm{E})$. This score is claimed to be easily understood (8) and to have a positive impact on nutritional health (9-14).

The Nutri-Score has been applied on industrial food products on a voluntary basis. Despite criticism emerging regarding its limits, especially because this score does not consider food additives, portion sizes, product origins, sustainable development or industrial ultraprocessing of food (15-17), the Nutri-Score is being imposed on food packaging as of January $1,2021$.

To the best of our knowledge, in France up to 2019, no study on the Nutri-Score had been implemented in a school setting to test this validated nutritional food quality rating system. In contrast, a recent study has shown that the workplace can contribute to healthy eating habits among employees through a simple food label using a positive approach (18).

In Belgium, a study on "food nudging" lasting 35 consecutive weeks was carried out in a university restaurant among students and catering staff. Week 1 was the control and the 4 following weeks reported 4 different nudges for each week (week 2: food triangle poster, week 2: green heart on fruit, week 3: substitution messages, week 4: message on fruit). A significant increase in fruit purchases among students was observed after 30 weeks. Half of the respondents in week 5 chose fruit for dessert. The increase in fruit purchases was stable after 35 weeks (19).

Given the simplicity and the positive outcomes of the Nutri-Score, we explored the possibility of using it, alone or coupled with other activities, as an intervention aimed at improving eating habits in a vocational school self-service restaurant. Thus, we assessed whether the NutriScore could be adapted to this population and raise awareness of healthier food choices among these students. This restaurant has multiple advantages for such research, including the fact that it welcomes students who represent a vulnerable population for their professional and personal situation (diseases, handicaps, financial problems). Moreover, they eat at the self-reservice restaurant every day.

Three research questions emerged: 1 . What impact can this simple and visual labeling system have on students' purchasing choices in a self-service restaurant? 2. By guiding students-especially those who may live with a chronic illness or may have a lower socio-economic condition--towards a more preferable choice thanks to this label, what influence can the label have on their daily food choices outside the self-service restaurant, during their shopping or at 
home? and 3. Is simplified labelling alone as effective as this same label coupled with face-toface nutritional counseling?

Regarding the first question, we hypothesize that choices will tend towards green Nutri-Score labels at the end of the study. For the second hypothesis, it would be preferable for the Nutriscore display in the restaurant to have a positive impact in other settings like food shopping. Finally, we would like to demonstrate the benefits of a setting where advice can be given in parallel to the Nutri-score. Therefore, we conducted this study from January to September, 2019 , in an attempt to answer our research questions and confirm our hypotheses.

\section{METHODS}

\section{Study conditions and population}

This study was conducted in a Centre de Rééducation Professionnelle/Vocational Rehabilitation Centre (CRP) whose attendees were mainly in a situation of food insecurity and/or living with a chronic disease (diabetes, obesity, other physical disabilities...). By considering all individual problems of the students, the vocational school professionals are committed to help them restart their professional lives.

The profile of vocational school students is not representative of the French population of students in general. On average, students are 43 years old and come from all over France, although $65 \%$ of them come from the same county. The principal mission of this vocational school is the professional and social rehabilitation of people with disabilities in the mainstream workplace. These students, after an accident or an illness, have been forced to leave their job and are obliged to consider professional reconversion.

After a preparatory period (refresher courses provided on site) of about 5 months, the vocational school offers, over a period of 14 to 23 months, diploma courses or integration assistance either to the ordinary work environment or to the protected work environment. The self-service restaurant of the vocational school serves slightly more than 200 people for lunch and slightly less than 50 people for dinner. Other students (about 27\%) eat in the school residence which has limited capacity. The catering service in charge of the school-based selfservice restaurant provides full access to recipes and allows the display of the Nutri-Score label on food items. This study lasted 6 months, with a 3-month time interval between each of the three sampling periods.

\section{Collected data}

\section{The Nutri-Score calculation and display}

The Nutri-Score has been calculated based on the nutritional information of the recipes proposed by the catering service throughout the experiment. If the nutritional information was missing, the dietician completed it with the values of the food or preparation (cooked values where they existed) assigned to them in the reference database on the nutritional composition of foods provided by the ANSES, (French acronym for National Agency for Food, Environment and Occupational Health and Safety), i.e., the CIQUAL (French acronym for Food Quality Information Center) (20).

Based on the information collected (nutritional composition in per cent of the product per $100 \mathrm{~g}$ of energy $(\mathrm{Kj})$, simple sugars $(\mathrm{g})$, saturated fatty acids $(\mathrm{g})$, sodium (mg), protein (g), fiber (g) and fruits, vegetables, legumes and oleaginous fruits), a dietician calculated the 
Nutri-Score of each product or preparation using the algorithm developed by Rayner et al. $(21,22)$ and validated in France (22-24) according to the French Public Health Agency (25).

\section{Dietary surveys of the adult obesity health network ROMDES}

We used a self-administered questionnaire validated by the adult obesity health network ROMDES (French acronym for Multidisciplinary Obesity Network of Ile-de-France Departments) (26). It is composed of 4 sections; each one including 6 questions: 2 sections concern the consumption frequencies of food groups (comparable to the recommendations of the National Nutrition Health Program, PNNS) (27), and the other 2 sections concern eating behavior. Each question proposes 5 Likert answer options (from "Very often" to "Never"). This results in two scores according to the choice of items: one for the estimation of "balance and variety" (rated out of 48); and the other one for the estimation of "behavior" (rated out of 48). The higher the score, the more the dietary balance or behavior is considered "healthy". This questionnaire was distributed at $\mathrm{T} 0$ in order to take a snapshot of the population on the estimation of food intake behavior. This questionnaire was given either in person at the selfservice location, or sent by email to students who wished to complete it. Once completed, it was left in a dedicated closed box at the entrance of the self-service restaurant within one week of distribution.

\section{The EPICES score}

The EPICES (French acronym for Assessment of Precariousness and Health Inequalities in Health Examination Centers) score assesses precariousness of individuals in health examination centers financed by the French Health Insurance (28). The questionnaire consists of 11 self-administered questions and the answer to each question is assigned a coefficient resulting in a continuous score, varying from 0 (no precariousness) to 100 (maximum precariousness). The EPICES score is linked to perceived socio-economic, behavioral and health indicators, is quantitative and allows longitudinal monitoring from the participant perspective. The EPICES score was collected at T0.

\section{The Flash Questionnaire}

For the purpose of the study, we developed a questionnaire that was designed to be simple, quick and understandable to all students. Several versions of this tool had been proposed by the paramedical care research center staff of Hospital Center Manhès. These versions were pre-tested with 5 professionals from the vocational school and 5 students in order to select the final version called the "Flash Questionnaire" for its speed of understanding and execution (about 2 minutes). The brevity of the questionnaire was important because we noticed during the dietary and behavioral survey at T0 that the vocational school students were resistant to answering a long questionnaire and yet it was important to obtain as many complete forms as possible. Subsequently, the final Flash Questionnaire was proposed to all students entering or leaving the self-service restaurant at T1 and T2. It included 7 items (6 questions plus an evaluative note) so that students could report their feelings and assess the impact and relevance of our study.

\section{Counseling service}

From T1, i.e., 3 months after the implementation of the Nutri-Score, we created a counseling service within the vocation school, close to the entrance-exit of the self-service restaurant, dedicated to information on nutrition, providing students with leaflets and flyers on the NutriScore and the consumption recommendations by the PNNS. Twice a week, a dietician offered 
advice and proposed games on nutrition. To encourage students to visit this counseling service, a program of different activities had been developed and disseminated.

\section{Label displaying}

We displayed on the weekly menu at the entrance-exit of the self-service restaurant and every day in front of each dish, the Nutri-Score logo as it was designed by Santé publique France (i.e., the French Public Health Agency) (25). On the menu visible to all students at the entrance to the self-service restaurant, all dishes had been labeled with the letter and its corresponding color according to the calculation made by the dietician. On the other hand, we displayed at the self-service counter only the Nutri-Score letters A (dark green color, corresponding to the healthiest food items) and B (light green color, corresponding to healthy food items). We adopted this choice for various reasons. First, we did not wish to make the consumers feel guilty about their choice. The aim was to accompany them towards information on the best nutritional quality of the dishes on offer, and thus towards a betterbalanced diet. Second, we were informed of the "Wellness Corporate » program of a French international company. This program included an intervention called "Green Apple label" conducted within the company worksite cafeterias as described elsewhere (28). This intervention was deliberately designed to indicate only low-calorie, healthy food items identified by a green logo, without emphasizing the poor nutritional quality of food items considered as less healthy and scored lower by other labeling systems like the Nutri-Score. Thus, this intervention used a positive nudging approach aimed at increasing consumption of healthier foods rather than providing negative feedback on individual nutritional choices (18).

Third, we feared that students of the vocational school would get lost with too many logos and, therefore, would not really pay attention to their choice. Finally, the major drawback that we noticed by displaying all the colors concerned the work of the catering staff who had to $\mathrm{reload} / \mathrm{change}$ the dishes in the refrigerated display cases. Thus, the labels in front of the windows of the counters indicating the Nutri-Score could be easily mixed up, put in the wrong place, and therefore no longer in front of their respective dishes. As a reminder, however, it was also possible for students to find all the letters of the Nutri-Score on the menus displayed and visible in the queue (29). We also wanted to emphasize the pleasure dimension coupled with healthy eating.

\section{Study conditions and population}

The study took place from January 2019 to September 2019, with two key periods of three months each (February-April and May-July). The month of January was devoted to the preparation of the study (scoring, authorizations, creation of questionnaires, posters...) and the last two months (August and September) to analysis and writing.

T0 was devoted to the collection of initial data, based on the ROMDES survey sent or distributed to consumers in order to evaluate the initial situation. In the first phase from T0 to T1, only the Nutri-Score label was displayed in the self-service restaurant. During this period, we asked the catering staff to collect the leftovers in dishes before and after the service in order to compare a possible evolution of food consumption towards healthier food items. At the end of this time (T1), we distributed the Flash Questionnaire at the entrance-exit of the restaurant. Given its speed, we immediately collected the questionnaires completed by students. In the second phase from T1 to T2, in addition to the same display (self-service restaurant, menus) of the Nutri-Score, we had set up a dietary counseling service with the presence of a dietician twice a week during the self-service restaurant opening hours. A schedule of fun activities had been put in place to encourage students to visit this easily 
accessible place. At the end of this time (T2), we distributed the same Flash Questionnaire at the entrance and exit of the restaurant, which we collected immediately.

In their daily work and in a program set up by the catering staff to fight against food waste, the self-service employees were required, at the end of the service, to note the difference between the quantity of portions of the dishes or the number of preparations cooked and made available to the guests before the service, and the quantity of remaining portions of these same dishes or the remaining number of the same preparations at the end of the service. The results were reported daily on a service sheet and were provided to us on a weekly basis. Figure 1 describes the methodology we employed and the project timeline.

We conducted our research according to the World Medical Association Declaration of Helsinki. Informed consent was provided by all participants.

Figure 1. Description of employed methodology and project timeline

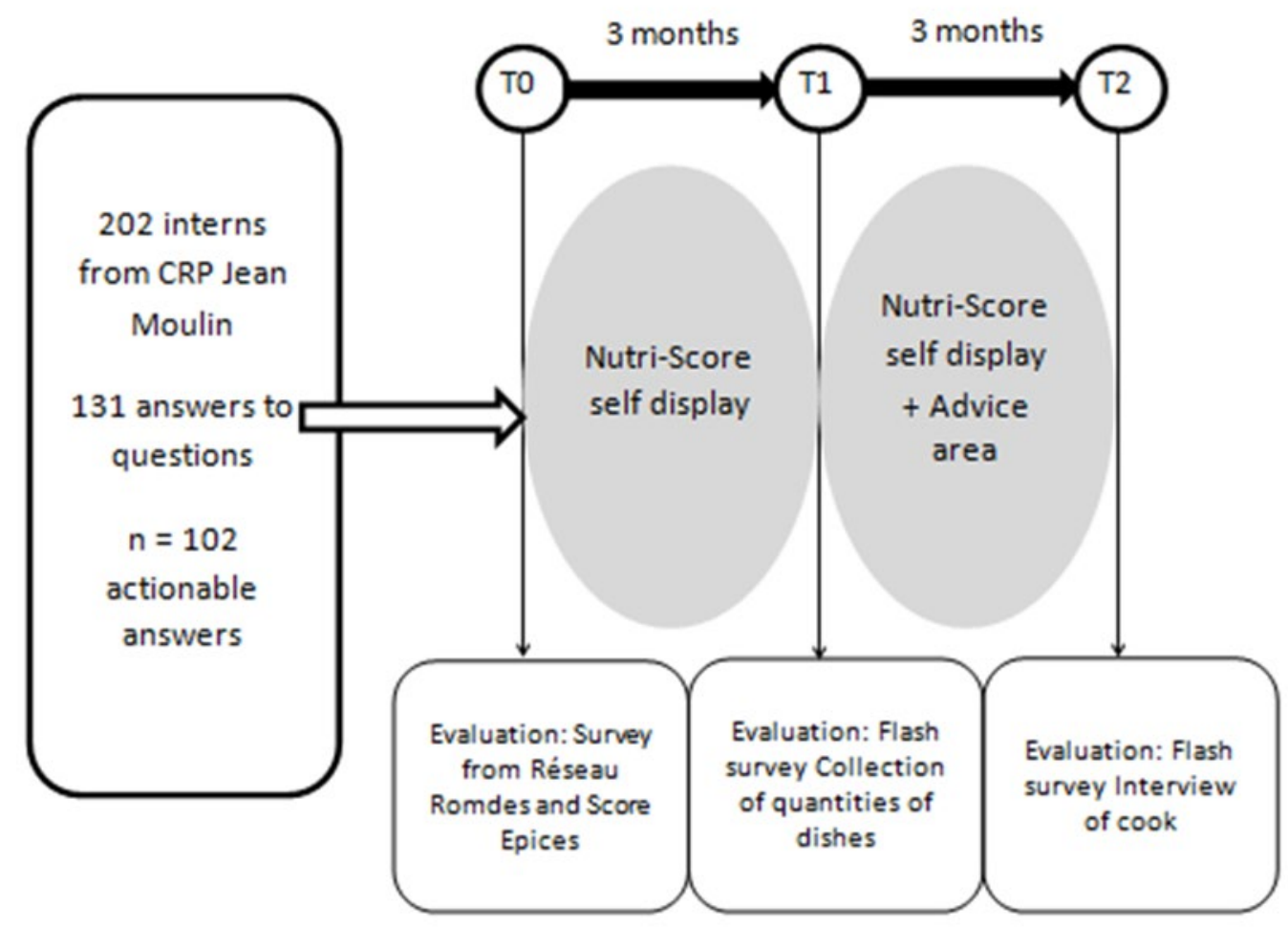

\section{Statistical analysis}

The results of the descriptive analysis were presented as numbers and percentages for qualitative data or as means (standard deviation) or medians (interquartile intervals) for continuous variables, depending on the characteristics of the observed distributions. The univariate comparisons between the two periods $\mathrm{T} 1$ and $\mathrm{T} 2$ used $\mathrm{Chi}^{2}$ tests for matched series for qualitative variables and the Student's T test for matched or ranked series of Wilcoxon for quantitative variables, depending on the application conditions. Based on the typical attendance at the self-service restaurant, we planned to include in this study 200 potential participants. The alpha risk was $5 \%(\mathrm{P}<$ or $=0.05)$. All analyses were performed using Addinsoft's XLSTAT and BioStaTGV software. 


\section{RESULTS}

\section{Description of the study population at T0}

We collected 131 responses from students, 102 of which were exploitable ( 29 were excluded since users returned incomplete questionnaires). Average age was 42.5 years [min 23. max 59]; EPICES score was 43 (rather high "multifactorial" precariousness or "multidimensional" insecurity - employment, income, housing, social ties, financial difficulties, etc.); the sample was composed of $69 \%$ women $(n=70) ; 59 \%$ had a pathology ( $n=60$ people in total), $30 \%$ $(\mathrm{n}=18)$ were overweight or obese; $27 \%(\mathrm{n}=16)$ had a cardiovascular disease (mainly hypertension) or hypercholesterolemia; $27 \%(n=16)$ had a physical disability; and $16 \%(n=10)$ had type 2 diabetes.

The scores (maximum score of 5 for each item), presented in Figure 2, were based on the initial ROMDES survey. They revealed positive results in terms of "balanced diet" according to the PNNS recommendations (21), i.e., appropriate consumption of water, starchy foods and animal proteins. However, fruit and vegetable consumption was rather low compared to the PNNS recommendations.

Other negative results included an excessive consumption of sausages, fried meats (or dishes with sauce) and sweet products (lowest score). However, rather positive scores were obtained for salt and alcohol consumption. As for the ROMDES survey, concerning users' profiles in terms of eating behaviors, the scores represented in Figure 2 were positive.

\section{Results at T1 after the sole display of the Nutri-Score at the self- service restaurant}

The majority of students interviewed using the first inter-study Flash Questionnaire (3 months after the beginning of the study) reported that they had not been influenced in their eating behavior, whether at the self-service restaurant or at home, by the Nutri-Score label during the period when it was displayed alone. However, there was a significant objective decrease in their consumption of sweet products. In fact, $55 \%$ of students self-reported that they had decreased their consumption of sweet products during this period (Figure 3).

\section{Measurement of leftovers, T1}

During the same period, the vocational school catering staff recorded the leftovers of the dishes in the self-service at the end of each service, noting down which Nutri-Score groups they belonged to, based on the menu displayed at the entrance of the self-service restaurant. There was a decrease in the leftovers for dishes with A and B score and, conversely, an increase in the leftovers for dishes without labels (i.e., scored C, D or E), which revealed a change in consumption and therefore in food choices.

\section{Results at T2: after the Nutri-Score display phase at the self- service restaurant coupled with the counseling service}

Following the implementation of the counseling service simultaneously with the continued Nutri-Score display, the same Flash Questionnaire was completed by students after 3 months. Beneficial changes appeared in particular with $2 / 3$ of the participants increasing their consumption of fruits and vegetables, a notable decrease in the consumption of sweet 
products and a slight increase in the practice of home cooking. However, while students still did not report that they had been influenced by the Nutri-Score label at the self-service restaurant, they apparently paid special attention to the Nutri-Score label when doing food shopping $(\mathrm{n}=91,89 \%)$.

Figure 2. Average self-assigned scores concerning users' eating behavior at T0

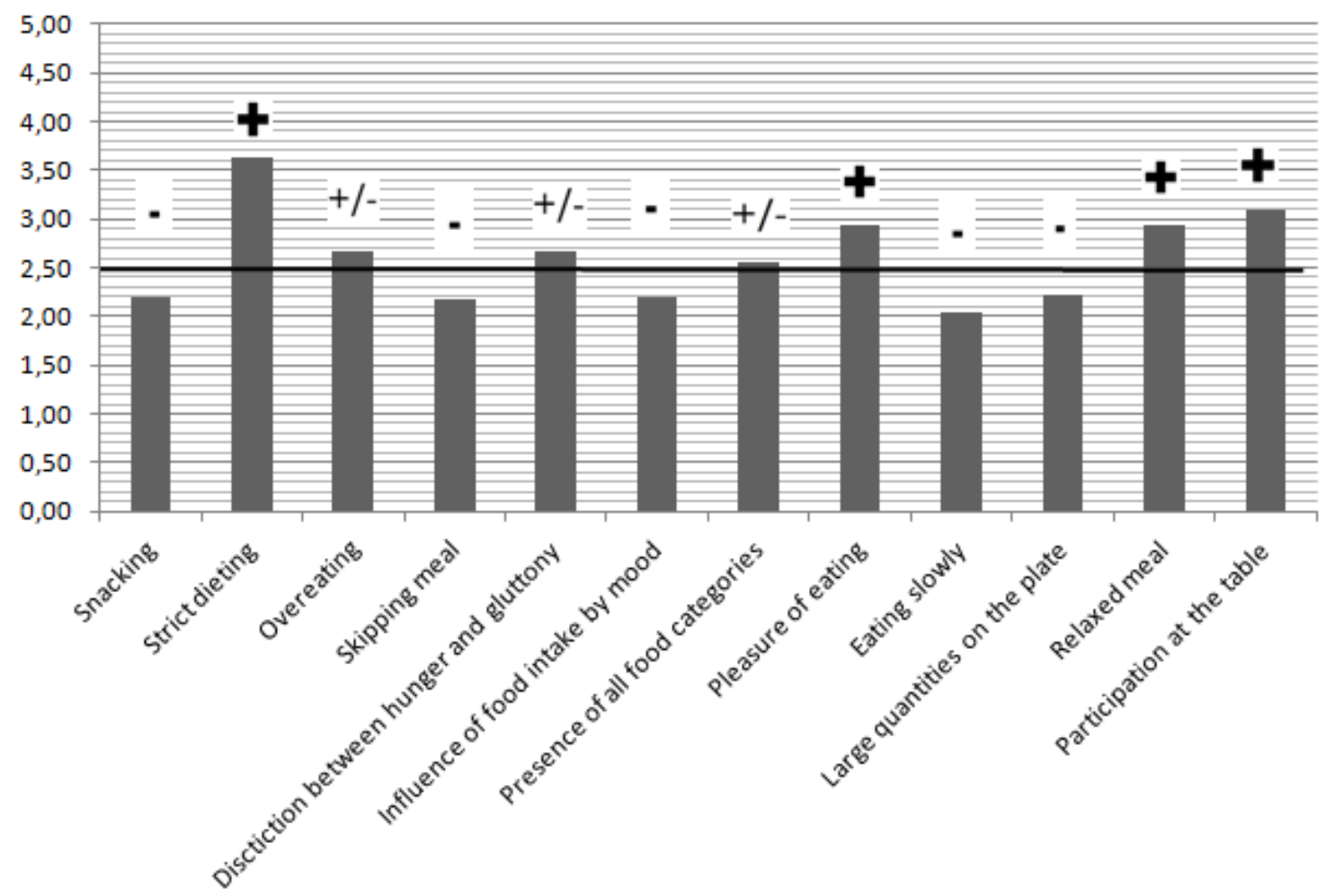

Snacking: eating outside of meals (such as "tea-time") that can unbalance the diet by an excessive intake of sweet products

Strict dieting: this refers to restrictive eating practices that are not medically justified

Overeating: overeating generally means eating beyond one's appetite

Skipping meals: skipping meals too often is not considered favorable to a balanced diet according to the recommendations of the French Ministry of Health

Distinction between hunger and gluttony: Today, nutrition experts consider that an individual who respects his food sensations by distinguishing between the sensation of hunger and gluttony can better control her/his weight Influence of food intake by mood: many eating disorders are due to food compulsions linked to mood or psychological disorders

Presence of all food categories: balanced eating is often defined as "eating a little bit of everything" by drawing from all food categories or groups

Pleasure of eating: eating should be considered a pleasure and not a burden.

Eating slowly: by eating slowly, we can better respect our food sensations and therefore eat in reasonable quantities

Large quantities on the plate: serving yourself large portions should be avoided when talking about a balanced diet

Relaxed meals: eating at the table, in a relaxed, non-stressful environment, promotes "healthy eating"

Participation at the table: meals at the table are important moments of exchange and conviviality and allow for real breaks while providing the body with the energy it needs

These positive changes are represented in Figure 4 comparing the evolutions in percentages of the answers "Yes" from T1 to T2. All evolutions were "positive" for "Yes" answers to all questions, and were, inversely, "negative" for "No" answers. This shows interesting changes 
with the introduction of the counseling service in addition to the display of the Nutri-Score label at the self-service restaurant.

Figure 3. Results at T1 (in \%) of « yes » and « no » responses collected by the Flash Questionnaire

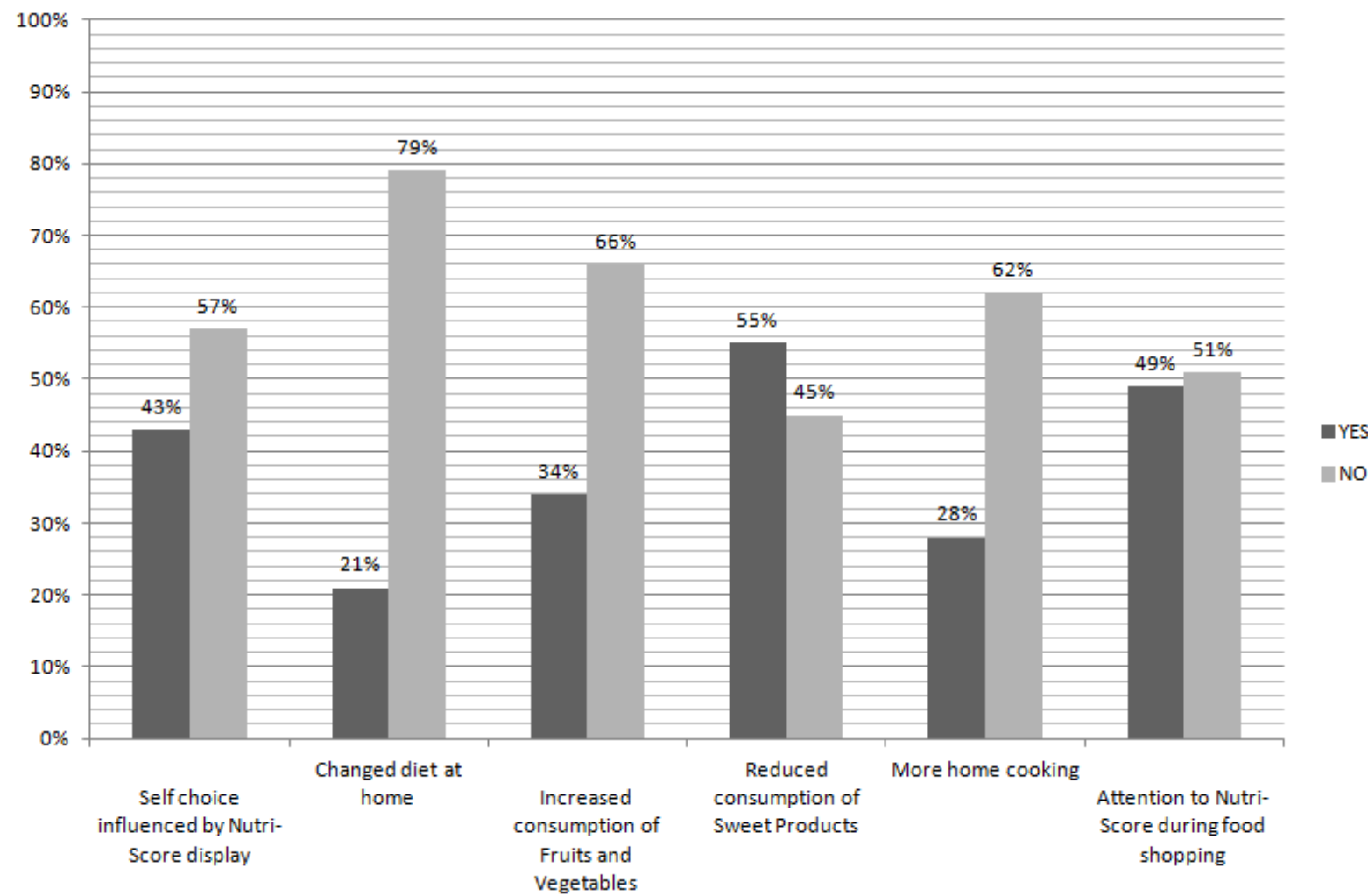

Figure 4. Evolution (in \%) of the dishes' leftovers at the end of the service according to their Nutri-score at T1

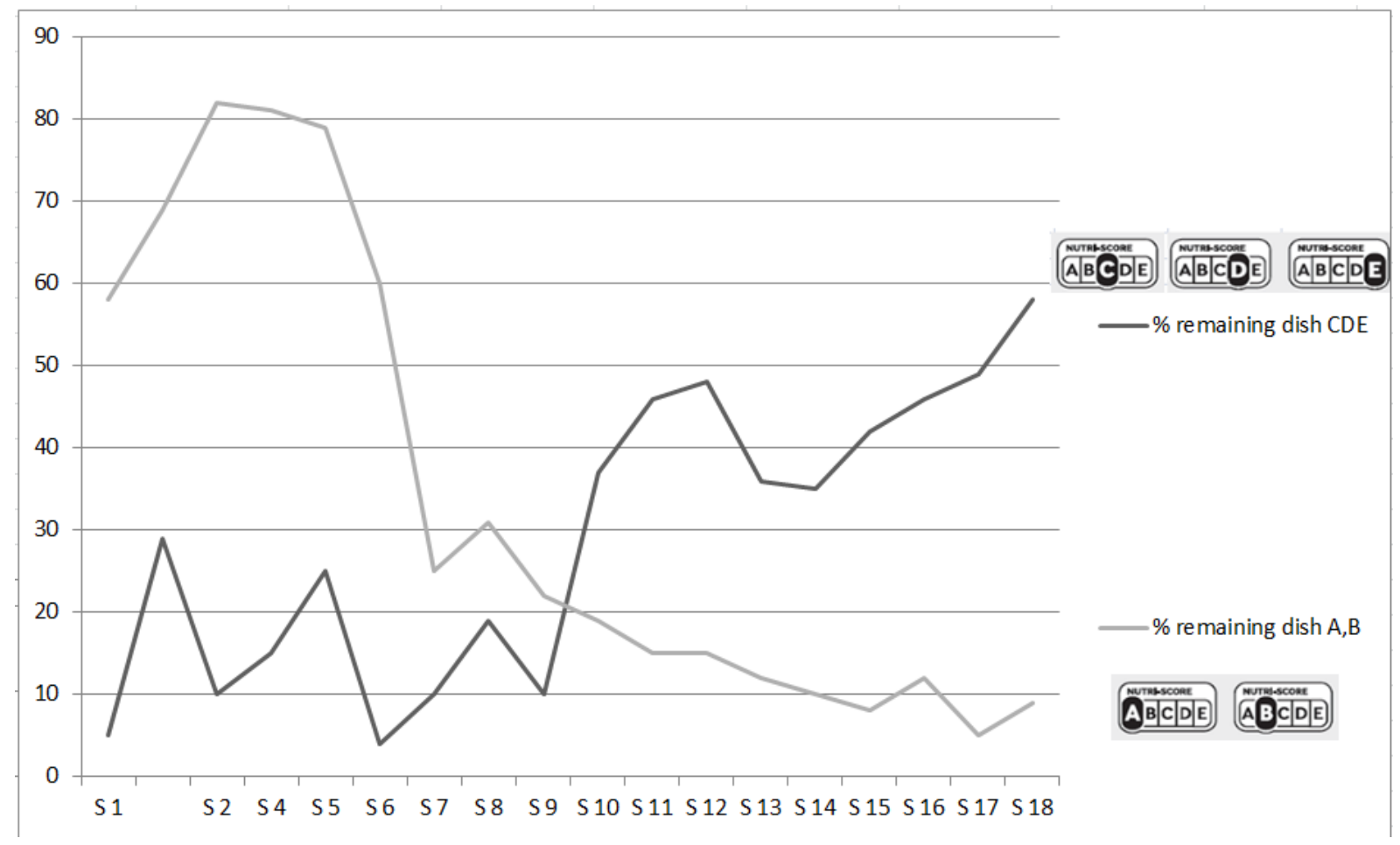


We also performed statistical analyses comparing "Yes" responses from T1 to T2 for each item (Figure 5). The implementation of the counseling service, compared to the Nutri-Score label display alone, resulting in a significant increase in consumption of fruit and vegetables $(\mathrm{P}<.001)$, in changing the diet at home $(\mathrm{P}<.001)$, more home cooking $(\mathrm{P}<.02)$, and had encouraged students to look for the Nutri-Score label on packaging more often when food shopping $(\mathrm{P}<.001)$. On the other hand, students did not feel that the Nutri-Score had a significant influence on their choices at the self-service restaurant $(\mathrm{P}=.6)$.

Figure 5. Evolution of changes deemed positive from T1 to T2 by item

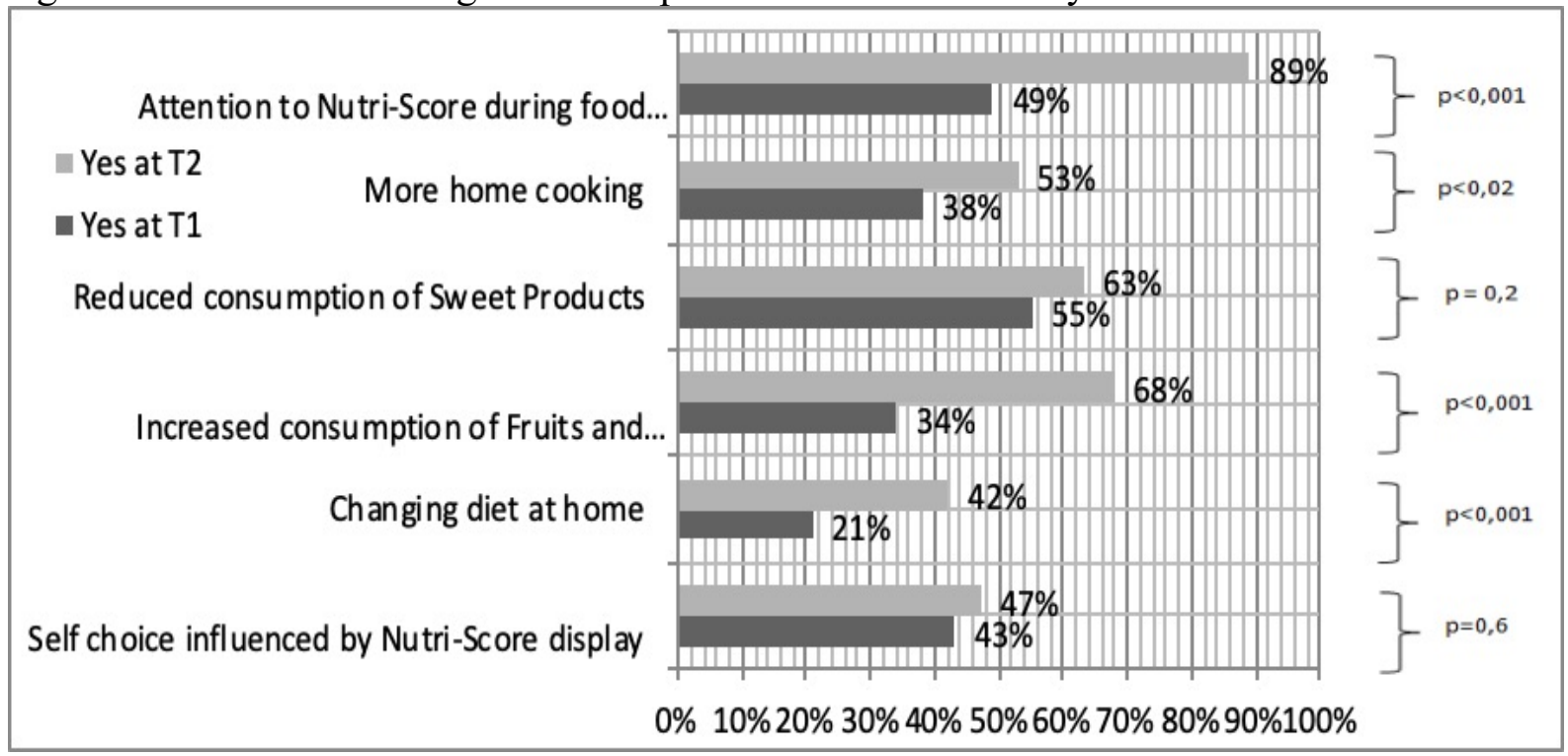

At the end of these 3 phases, we questioned the catering staff in order to collect their opinions. The interview with the main cook of the center confirmed that an additional workload was perceived by his team, in particular by the waitress who displayed the Nutri-Score at the beginning of each service. Likewise, the kitchen team in place during the service had to regularly explain the use of the Nutri-Score to the students, despite posters having been displayed 3 weeks before explaining the project and the meaning of the letters A and B of the Nutri-Score. According to the cook, these posters were not visible and they were considered by the students to be just decoration. According to him, students needed to be guided to finally read them.

For the cook, displaying only the A and B of the Nutri-Score at the self-service as explained in the "method" paragraph was not the right solution. He would have preferred that all the letters were displayed (C, D and $\mathrm{E}$ in addition to $\mathrm{A}$ and $\mathrm{B}$ ). He pointed out to us that despite the display of all the letters on the menu, this was not visible enough and did not affect the consumer enough.

His argument for saying that this was a negative point was the fact that the consumer diverted his view from the scoring. Example: "I take the cold cuts; there is no A and B, and since there are no other notes, then it is not a negative food".

The cook also told us that since the Nutri-Score project was set up, he was himself attentive to the Nutri-Score. He also said he paid much more attention to the way he cooks. He has been trying since the experiment to reduce, in particular, additions of fat, salt and sugar. 


\section{DISCUSSION}

Throughout the study, we realized how essential the involvement of catering staff was for the success of the experiment. Indeed, they were present throughout the process and were part of the smooth running of the entire study. First of all, they were involved in the refilling of the dishes, which had to be placed so as to correspond to the concerned Nutri-Score letter.

Second, they were actively involved in calculating the leftovers at the end of the service as we mentioned in the methods. Finally, they were often questioned by students in the self-service restaurant about the Nutri-Score. All these actions relating to their involvement must be considered when observing the positive results of our study. It is important that the catering staff is fully involved in such an action from the outset. Moreover, the "interview" with the catering cook at the end of the study confirmed this idea: despite his reticence at the beginning of the project, he admitted in the end that he would have liked to be even more involved in our Nutri-Score study. Moreover, this same cook appreciated our study since he had already thought of modifying his recipes in line with positive Nutri-Score labels.

So, if the Nutri-Score front-labeling may represent a strong incentive for the agro-industry to reformulate its products in order to improve their nutritional quality, the same concept is certainly true for the catering industry, where cooks can therefore use the Nutri-Score calculation to improve the final balance of their recipes.

During the first part of the study, which only consisted of applying the Nutri-Score label to the self-service counter and to the menus via a few posters explaining it, students felt they made only modest changes, whereas the catering staff's calculation of the leftovers in the selfservice counter suggested the changes were greater. From the results of the questionnaires in T1, we could not explain this difference in perception between the feelings of students ("I do not pay attention to the display of the Nutri-Score at the self") and the leftovers noted down by the catering staff. More analysis is needed in future research to explain this paradox. It is possible, however, that the students did not choose them because indeed they did not like the dishes offered.

During the second phase, when the counseling service was added, the results were more visible and more straightforward. Thanks to the Flash Questionnaire, we were able to understand that students themselves felt several positive changes (except for the influence of the display of the Nutri-Score label during their lunches and dinners at the self-service restaurant).

It should also be considered that the awareness of the display of the Nutri-Score label in the self-service restaurant allowed the majority of students to pay more attention to its presence on food packaging during their food shopping. However, all these improvements were more significant when the Nutri-Score display was combined with the counseling service. This effective combination between these two types of actions ("display" and "information") showed that effective nutritional interventions are multi-component ones, as suggested in previous studies (30).

Our study can however be criticized for having opted only for displaying the letters A and B, because we did not want to blame students for their food choices, but rather nudge them towards healthier choices. Moreover, the collection of the first ROMDES questionnaires at T0 was not always easy: fear of being "spied on", feeling that the questionnaire was too long (whereas, in practice, it took 5 minutes to be completed), little communication, etc. were 
considered by users as the main difficulties of the questionnaire. Our study can also appear as incomplete, since we could not give the ROMDES questionnaire again at T1, because it was considered as too long and that students in September were not the same as those in the first part of the study, as many of them had completed their training.

It should also be considered that concentrating on the choice of a balanced diet is difficult at mealtime, as users have little time to eat and prefer eating fast and talking in order to take a real break. This study had also required a significant additional workload for the catering staff and, although it was difficult to motivate them at first, they were of considerable help in the end. The seasonality as a bias was also not taken into account, yet we know that during summer the consumption of raw vegetables and fruits is naturally increased, which may explain the fact that the catering staff noted an increase in dishes A and B during this period (May-July).

Displaying the Nutri-Score label in a vocational school-based mass catering appeared to be more difficult than in the food industry where this labeling system is already well established. In fact, in mass catering, conditions are more variable and the same recipe, depending on the way it is prepared, can display a positive or negative Nutri-Score label. By simply adding butter or cream or salt to the preparation, a recipe which is usually rated with a "A" could be rated with a "C" according to national nutritional standards. Similarly, the calculation of the nutritional values given by mass catering service is regularly based on "raw" food items and, sometimes, by portion to be served, which is different from pre-packaged food with established ingredients and weights. However, when food items are cooked, the nutritional values can change. In mass catering, the calculation of the Nutri-Score is based on $100 \mathrm{~g}$ of finished products or preparations. Therefore, the dietician of our counseling service had to juggle between the CIQUAL (French Food Quality Information Center) (20) database of cooked foods and the additional explanations given by the cook on any particular recipe.

Likewise, despite the pre-calculation of the Nutri-Score, which might be considered sufficient, such calculation might have been modified by the consumers themselves. In fact, at the end of the self-service counter, there were additional condiments (vinaigrette, ketchup, mayonnaise, barbecue sauce, salt, etc.) whose addition and dosage could modify the basic Nutri-Score attributed to each food portion.

These remarks from our pilot study were taken into account by authorities; recently, the French Health Ministry launched a call for projects to support experiments testing the adaptation of the Nutri-Score label to the context of collective and commercial catering. The projects should aim to standardize the calculation of the Nutri-Score labels for catering recipes through the creation of a unique tool. For instance, the Nutri-Score labels for meat will depend on the type of meat (piece, origins...) and the cooking (hoven, frying pan, grill...), and the Nutri-Score labels will be specified for standard quantities of dressing.

In view of the overall positive results not only of our experiment, but also of some studies carried out abroad concerning intervention strategies in school-based collective catering using simple informal labels more or less identical to ours $(18,19,29)$, it is essential to continue this type of research, by combining it with counseling so that its effectiveness can be optimized. It is important for future similar projects in school-based mass catering to consider information, mutual aid and inter-professional training. 


\section{CONCLUSIONS}

The display of the Nutri-Score label in a vocational school mass catering had positive impacts on the daily dietary balance of students, in particular concerning the increase in the consumption of fruits and vegetables and the decrease in the consumption of sweet products. The influence of the labeling at the self-service restaurant may have been underestimated by the students, since they reported not having been influenced in their choice by the label, whereas the leftovers noted down by the self-service restaurant catering staff suggested greater changes were made. Our positive results were more significant when the labeling experiment was combined with an on-site counseling and information service. Thus, our study suggests that it is more effective to implement a multi-component intervention to promote good eating habits. This study also suggests more research is needed in the field of public health and prevention concerning nutrition based on this model. Finally, the study has also required a certain amount of additional work for the catering staff, and it therefore seems important for future similar studies in mass catering services to take into account the involvement of catering staff.

\section{REFERENCES}

(1) Cecchini M, Warin L. Impact of food labelling systems on food choices and eating behaviours: a systematic review and metaanalysis of randomized studies. Obes Rev 2016;17(3):201e10.

(2) Journal Officiel de la République Française. Arrêté du 31 octobre 2017 fixant la forme de présentation complémentaire à la déclaration nutritionnelle recommandée par l'Etat en application des articles L. $3232-8$ et R. 3232-7 du code de la santé publique. JORF $\mathrm{n}^{\circ} 0257$, 2017.

(3) Julia C, Etile F, Hercberg S. Front-of-pack Nutri-Score labelling in France: an evidence-based policy. Lancet Public Health 2018;3:e164.

(4) Arambepola C, Scarborough P, Rayner M. Validating a nutrient profile model. Public Health Nutr 2008;11:371-8.

(5) Rayner M, Scarborough P, Stockley P, Boxer A. Nutrient profiles: Development of Final Model. Final Report [online]. London: Food Standards Agency, 2005.

https://www.researchgate.net/profile/PeterScarborough/publication/266447771 Nutrient profiles Development of Final Model Final Report/links/5440d4fe0cf218719077d82d/Nutrient-profiles-Development-of-Final-ModelFinal-Report.pdf

(6) Julia C, Kesse-Guyot E, Touvier M, Mejean C, Fezeu L, Hercberg S. Application of the British Food Standards Agency nutrient profiling system in a French food composition database. Br J Nutr 2014;112:1699-705.

(7) Anses. Evaluation de la faisabilité du calcul d'un score nutritionnel tel qu'élaboré par Rayner et al. Rapport d'appui scientifique et technique. Paris: Anses. 2015.

(8) Ducrot P, Méjean C, Julia C, Kesse-Guyot E, Touvier M, Fezeu L, et al. Effectiveness of Front-Of-Pack Nutrition Labels in French Adults: Results from the NutriNet-Santé Cohort Study. PLoS ONE 2015;10(10):e0140898.

(9) Egnell M, Kesse-Guyot E, Galan P, Touvier M, Rayner M, Jewell J, Breda J, Hercberg S, Julia C. Impact of Front-of-Pack Nutrition Labels on Portion Size Selection: An Experimental Study in a French Cohort. Nutrients 2018;10:1268.

(10) Egnell $\mathrm{M}$ et al. Front-of-Pack Labeling and the Nutritional Quality of Students' Food Purchases: A 3-Arm Randomized Controlled Trial. American Journal of Public Health 2019;109(8):1122-1129. 
(11) Adriouch S, Julia C, Kesse-Guyot E, Ducrot P, Péneau S, Méjean C, Assmann K, Deschasaux M, Hercberg S, Touvier M. Association between a dietary quality index based on the food standard agency nutrient profiling system and cardiovascular disease risk among French adults. International Journal of Cardiology 2017;234:22-27.

(12) Egnell M, Crosetto P, d'Almeida T, Kesse-Guyot E, Touvier M, Ruffieux B, Hercberg $\mathrm{S}$, Muller L, Julia C. Modelling the impact of different front-of-package nutrition labels on mortality from non-communicable chronic disease. Int J Behav Nutr Phys Act 2019;16:56. (13) Andreeva VA, Egnell M, Galan P, Feron G, Hercberg S, Julia C. Association of the Dietary Index Underpinning the Nutri-Score Label with Oral Health: Preliminary Evidence from a Large, Population-Based Sample. Nutrients. 2019;11(9).

(14) Deschasaux M, Julia C, Kesse-Guyot E, Lécuyer L, Adriouch S, Méjean C, Ducrot P, Péneau S, Latino-Martel P, Fezeu L. Are self-reported unhealthy food choices associated with an increased risk of breast cancer? Prospective cohort study using the British Food Standards Agency nutrient profiling system. BMJ Open 2017;7(6):e013718.

(15) Fardet A. Prévention des maladies chroniques : pour une classification holistique des aliments selon leur degré de transformation. Nutritions \& Endocrinologie 2017;15(83):85-88.

(16) Scarborough P, Matthews A, Eyles H, Kaur A, Hodgkins C, Raats MM, Rayner M. Reds are more important than greens: How UK supermarket shoppers use the different information on a traffic light nutrition label in a choice experiment. International Journal of Behavioral Nutrition and Physical Activity 2015;12(1):1-9.

(17) Le quotidien du Médecin, dossier « Un outil jugé peu adapté en clinique. Face au Nutri-Score, les médecins restent à convaincre », Publié le 21/10/2019.

https://www.lequotidiendumedecin.fr/actus-medicales/recos-pratique/face-au-nutri-score-lesmedecins-restent-convaincre

(18) Montigni I, Prevot F, Fontvieille AM, et al. Using Positive Nudge to Promote Healthy Eating at Worksite A Food Labeling Intervention Journal of Occupational and Environmental Medicine. 2020;62(6):e260-6.

(19) VERMOTE M, et al. The effect of nudges aligned with the renexed Flemish Food Triangle on the purchase of fresh fruits: An on-campus restaurant experiment. Appetite 2020;144:104479.

(20) https://ciqual.anses.fr/

(21) FSA. Nutrient Profiling Technical Guidance, 2011.

(22) Arambepola C, Scarborough P, Rayner M. Validating a nutrient profile model. Public Health Nutrition 2007;11:371-378.

(23) Julia C, Touvier M, Méjean C, Ducrot P, Péneau S, Hercberg S, Kesse-Guyot E.

Development and validation of an individual dietary index based on the british food standard agency nutrient profiling system in a French context. The Journal of Nutrition 2014;144(12):2009-17.

(24) ANSES. Évaluation de la faisabilité du calcul d'un score nutritionnel tel qu'élaboré par Rayner et al. Paris: Agence Nationale de Sécurité Sanitaire alimentation, environnement, travail (ANSES); 2015.

(25) https://www.santepubliquefrance.fr/determinants-de-sante/nutrition-et-activitephysique/articles/nutri-score

(26) Lamandé JP, Raison J, et al. Comparaison des caractéristiques de patients obèses hospitalisés ou pris en charge en ambulatoire par un réseau. Réseau Obésité Multidisciplinaire des Départements franciliens. Médecine des maladies Métaboliques 2011;5(5):559-566.

(27) Ministère de la santé. Programme National Nutrition Santé, 2011-2015. https://www.mangerbouger.fr/ 
(28) Sass C, Moulin JJ, Guéguen R, Abric L, Dauphinot V, Dupré C, et al. Le score Epices: un score individuel de précarité. Construction du score et mesure des relations avec des données de santé, dans une population de 197389 personnes. BEH 2006;14:93-96.

(29) Chen HJ, Weng SH, Cheng YY, Lord AYZ, Lin HH, Pan WH. The application of traffic-light food labelling in a worksite canteen intervention in Taiwan. Public Health 2017;150:17-25.

(30) Maes L, Van Cauwenberghe E, Van Lippevelde W, Spittaels H, De Pauw E, Oppert JM, De Bourdeaudhuij I. Effectiveness of workplace interventions in Europe promoting healthy eating: a systematic review. European Journal of Public Health 2012;22(5):677-683. 